\title{
Awareness Survey about Colorectal Cancer in Students of M. Phil Biotechnology at Bahauddin Zakariya University, Multan, Pakistan
}

\author{
Muhammad Imran Qadir*, Ghalia Batool Alvi \\ Bahauddin Zakariya University, Pakistan
}

*Corresponding author: Muhammad Imran Qadir, Institute of Molecular Biology \& Biotechnology, Bahauddin Zakariya University, Multan, Pakistan

Submission: 啡 March 28, 2018; Published: 眥 April 24, 2018

\begin{abstract}
Cancer of colon and rectum is collectively called Colorectal Cancer (CRC). It is considered as the second most lethal cancer after lung cancer. One of the symptoms of CRC is rectal bleeding. A survey was conducted to evaluate the level of awareness among M. Phil Biotechnology students. The key idea of this survey was to develop understanding about this deadly disease. A questionnaire consisting of 15 basic questions about CRC was developed. Total 37 students filled the questionnaire; 31 were females while 6 were males. Results clearly demonstrated the unawareness of the students towards this lethal CRC. In the first section about causative agents; $78 \%$ of the students answered that CRC is a bacterial disease. Next portion was about the victims of CRC in your surroundings; more than $95 \%$ of students never witnessed any case of CRC in their family or vicinity. 3rd category was about transmission route of CRC; according to $38 \%$ of students, CRC can be transferred from affected parents to offspring and in the last section which was about possible treatments of CRC; $97 \%$ students answered that CRC can be treated with medication only while $68 \%$ answered that there is a need of surgical treatment for CRC. Therefore, it is very important to spread awareness among people.
\end{abstract}

Keywords: Colorectal cancer; Lethal; Survey; Awareness level; Less Knowledge; Cancer; Genetic

\section{Introduction}

Cancer is an uncontrollable and unchecked division of cells [1]. Cancer can occur in any part of body. The cancer of colon and rectum is collectively called Colorectal Cancer (CRC). Colorectal cancer is third most common type of cancer after lung and prostate cancer. The American Cancer Society estimates the cases of colorectal cancer to be 0.15 Million in 2018 [2]. Colorectal cancer can have different types depending upon the nature of cells and type of cancer. It can either be malignant tumour or metastases cancer. Colorectal cancer usually has four types. These are adenocarcinomas, carcinoid tumours, gastrointestinal lymphoma, and gastrointestinal stromal tumours [3]. There are many risk factors that can lead to colorectal cancer. Inflammatory bowel disease is one of the main causes of Methodology

Table 1: Questionnaire to evaluate Level of awareness about Colorectal Cancer in M. Phil Biotechnology Students at IMBB, BZU, Multan. colorectal cancer. Some genetic disorders and diet factors are also involved in inducing colorectal cancer [4]. There are several symptoms associated with colorectal cancer. One of the leading symptoms is rectal bleeding [5]. It also involves discomforted bowel feeling and blood in stools [6]. Another associated symptom is abdominal pain and a sudden weight loss [7].

A survey was conducted to evaluate the level of awareness among M. Phil Biotechnology students. The central idea of this study was to establish the understanding of Colorectal Cancer among M. Phil Biotechnology Students of IMBB, Bahauddin Zakariya University (BZU), Multan.

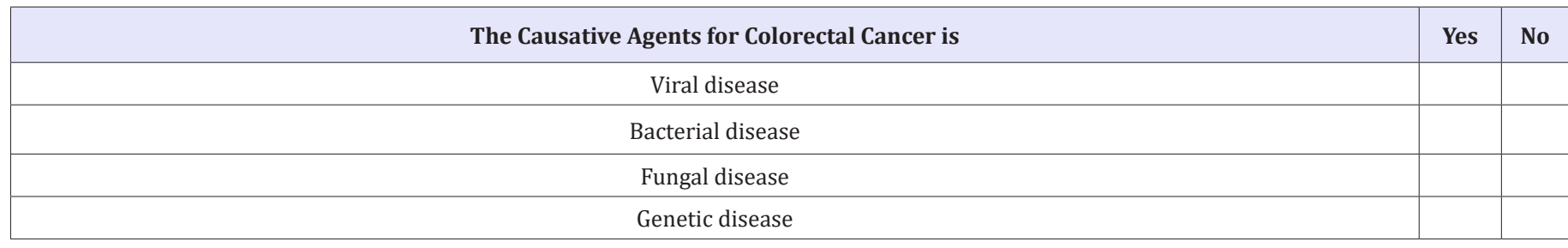




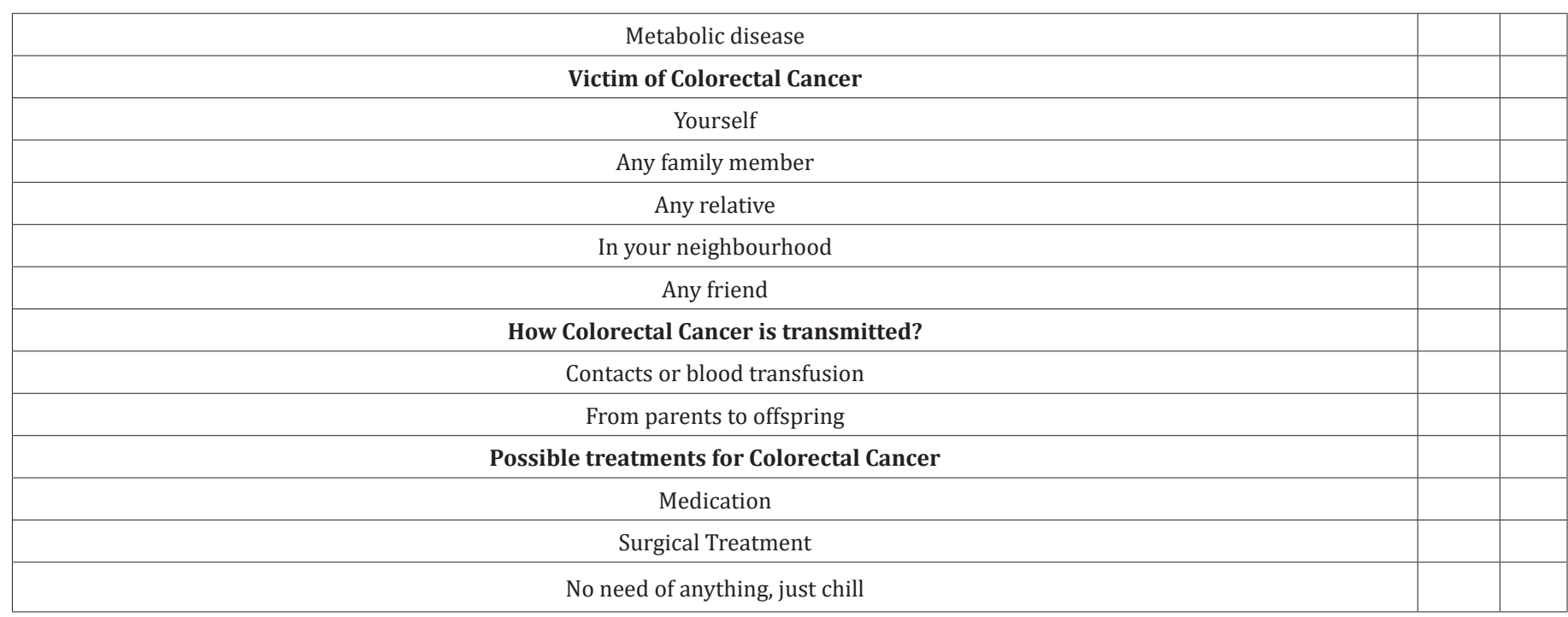

A questionnaire containing 15 basic questions (Table 1) about Colorectal Cancer was designed. The key principle of that questionnaire was to broaden the awareness about CRC, its risk factors, possible victims of CRC and the possible treatments of this dangerous disease among the Students of M. Phil Biotechnology at Institute of Molecular Biology \& Biotechnology (IMBB). Total $37 \mathrm{M}$. Phil students of IMBB had filled that questionnaire. Out of these 37 students 31 were females and 6 were males. The basic criteria for inclusion was the M. Phil Biotechnology Students of IMBB,

Table 2: Level of understanding about the Causative Agents for Colorectal Cancer: Views of M. Phil Biotechnology Students at IMBB, BZU, Multan.

\begin{tabular}{|c|c|c|c|c|c|c|c|}
\hline \multirow{2}{*}{ The Causative Agents for Colorectal Cancer is } & \multicolumn{2}{|c|}{ Male } & \multicolumn{2}{c|}{ Female } & \multicolumn{2}{c|}{ Total } \\
\hline & & Yes & No & Yes & No & Yes & No \\
\hline 1. & Viral disease & $17 \%$ & $83 \%$ & $32 \%$ & $68 \%$ & $30 \%$ & $70 \%$ \\
\hline 2. & Bacterial disease & $83 \%$ & $17 \%$ & $77 \%$ & $23 \%$ & $78 \%$ & $22 \%$ \\
\hline 3. & Fungal disease & $17 \%$ & $83 \%$ & $32 \%$ & $68 \%$ & $30 \%$ & $70 \%$ \\
\hline 4. & Genetic disease & $17 \%$ & $83 \%$ & $32 \%$ & $68 \%$ & $30 \%$ & $70 \%$ \\
\hline 5. & Metabolic disease & $17 \%$ & $83 \%$ & $35 \%$ & $65 \%$ & $32 \%$ & $68 \%$ \\
\hline
\end{tabular}

Colorectal cancer is a viral disease or not? $17 \%$ of the males answered this question Yes, while $83 \%$ of the males said that CRC is not a viral disease. In case of females, $32 \%$ of them answered yes and $68 \%$ answered NO. The overall result of this question is that; according to $30 \%$ of the students CRC is a viral disease but according to $70 \%$ of the students CRC is not a viral disease. Colorectal cancer is a bacterial disease or not? In case of males the result is totally reverse to that in the first question. 83\% of males answered Yes, CRC is a bacterial disease but according to $17 \%$ of males the answer is No. In females $77 \%$ answered yes, while $23 \%$ answered No, CRC is not a bacterial disease. The overall result shows that according to $78 \%$ of the students the answer to this question is Yes but $22 \%$ answered that CRC is not a bacterial disease. Now the third question is; Colorectal cancer is a fungal disease or not? $17 \%$ of the males answered Yes CRC is a fungal disease but $83 \%$ answered No. In case of females, 32\% filled the column Yes but $68 \%$ filled the No column. So here the overall result is; $30 \%$ of the students
Bahauddin Zakariya University (BZU), Multan, while the criteria for exclusion was not to include any student other than M. Phil Biotechnology i.e. Students of Bachelor Programme were excluded from this survey.

\section{Results and Discussion}

Results were collected from all the students and calculated in the form of percentages. Table 2 consists of the response and understanding of the students to the question about causative agents for Colorectal Cancer.

thought that CRC is a fungal disease but 70\% thought that it is not a fungal disease. Colorectal cancer is a genetic disease or not? The result is same as that in case of fungal disease i.e. $17 \%$ of males answered Yes and $83 \%$ answered No. Same is the case in females, $32 \%$ answered that CRC is a genetic disease and $68 \%$ answered No. The overall result is also same i.e. $30 \%$ considered it to be genetic disease and $70 \%$ answered that it is not a genetic disease. Now the last question of Table 2 is Colorectal cancer is a metabolic disease or not? $17 \%$ of the males answered that CRC is a metabolic disease but $83 \%$ answered CRC is not a metabolic disease. $35 \%$ of the females answered Yes, while $65 \%$ answered No. The overall percentage is as follows: according to $32 \%$ students CRC is metabolic disease but $68 \%$ of the students answered that CRC is not a metabolic disease. Here the results are shown in the Table 2. Shows the response and awareness level of students about the victims of CRC in their surroundings Table 3. 
Table 3: Level of understanding about the Victims and Sufferers of Colorectal Cancer: Views of M. Phil Biotechnology Students at IMBB, BZU, Multan.

\begin{tabular}{|c|c|c|c|c|c|c|}
\hline \multirow[t]{2}{*}{ Victim of Colorectal Cancer } & \multicolumn{2}{|c|}{ Male } & \multicolumn{2}{|c|}{ Female } & \multicolumn{2}{|c|}{ Total } \\
\hline & Yes & No & Yes & No & Yes & No \\
\hline Yourself & $0 \%$ & $100 \%$ & $3 \%$ & $97 \%$ & $3 \%$ & $97 \%$ \\
\hline Any Family Member & $0 \%$ & $100 \%$ & $0 \%$ & $100 \%$ & $0 \%$ & $100 \%$ \\
\hline Any Relative & $0 \%$ & $100 \%$ & $3 \%$ & $97 \%$ & $3 \%$ & $97 \%$ \\
\hline In Your Neighbour & $0 \%$ & $100 \%$ & $6 \%$ & $94 \%$ & $5 \%$ & $95 \%$ \\
\hline Any Friend & $0 \%$ & $100 \%$ & $6 \%$ & $94 \%$ & $5 \%$ & $95 \%$ \\
\hline
\end{tabular}

The first question is about yourself i.e. have you ever suffered from CRC? All the males answered No to this question so, here the result is $100 \%$ No but $3 \%$ of the females answered that they have suffered from CRC, while $97 \%$ answered No. The overall percentage is as follows: $3 \%$ answered that they have suffered from CRC, while 97\% answered that they have not suffered from CRC. The next question is about family. Have your family ever suffered from CRC? All the males and females answered No in this question so the overall result is $100 \%$ No that no one family suffered from CRC. Have your any relative ever suffered from CRC? All the males answered No so the result is $100 \%$ No. $3 \%$ of the females said that their relatives have been suffered from CRC but $97 \%$ said No. The overall result is that $3 \%$ answered their relatives have suffered, while $97 \%$ said that their relatives have not suffered. Have your any neighbour ever been suffered from CRC? Here the answer is also $100 \%$ No in case of males, while in the case of females 6\% answered Yes their neighbours have been suffered from CRC but $94 \%$ answered No. The collective result is that $5 \%$ of the students answered that their neighbours have suffered, while 95\% answered that their neighbours have not suffered from CRC. Have your any friend ever been suffered from CRC? In case of males, the answer is $100 \%$ No. According to females, $6 \%$ of them answered Yes and 94\% answered No. The entire result in this category is $5 \%$ students answered Yes, their friends have suffered from CRC and 95\% answered that their friends have not suffered from CRC. All the results are given away in the Table 3 that shows the understanding and awareness level of the students about the victims of this dangerous disease CRC. Table 4 represents the data regarding the understanding level of students about the transmitting mode of CRC.

Table 4: Level of understanding about the Transmitting mode of Colorectal Cancer: Views of M. Phil Biotechnology Students at IMBB, BZU, Multan.

\begin{tabular}{|c|c|c|c|c|c|c|}
\hline $\begin{array}{c}\text { How Colorectal Cancer is } \\
\text { Transmitted? }\end{array}$ & \multicolumn{2}{|c|}{ Male } & \multicolumn{2}{c|}{ Female } & \multicolumn{2}{c|}{ Total } \\
\hline & Yes & No & Yes & No & Yes & No \\
\hline $1 . \quad 17 \%$ & $83 \%$ & $10 \%$ & $90 \%$ & $11 \%$ & $89 \%$ \\
\hline $2 . \quad \begin{array}{c}\text { Contact or } \\
\text { blood transfusion }\end{array}$ & $17 \%$ & $83 \%$ & $41 \%$ & $59 \%$ & $38 \%$ & $62 \%$ \\
\hline $\begin{array}{c}\text { Parents to } \\
\text { offspring }\end{array}$ & $17 \%$ \\
\hline
\end{tabular}

Is CRC transmitted through contact or blood transfusion? 17\% of the males answered to this question Yes, while $83 \%$ of them answered No. In females, $10 \%$ of them filled the column Yes, while $90 \%$ filled the second column i.e. No. The total combined result is as follows: $11 \%$ of the students answered that it can be transmitted through blood transfusion, while $89 \%$ of the students answered No. Is CRC transmitted through parents to offspring? The result of males is same as that in the case of contact or blood transfusion i.e. $17 \%$ of the males answered Yes, while $83 \%$ answered No. According to females, $41 \%$ of them answered Yes, while the rest of $59 \%$ answered No. The collective result of males and females is as follows: $38 \%$ of the students answered that it can be transferred from parents to offspring, while $62 \%$ of them answered that it can't be transmitted.

Table 5: Level of understanding about the possible treatments for Colorectal Cancer: Views of M. Phil Biotechnology Students at IMBB, BZU, Multan.

\begin{tabular}{|c|c|c|c|c|c|c|}
\hline $\begin{array}{c}\text { Possible Treatments } \\
\text { for Colorectal Cancer }\end{array}$ & \multicolumn{2}{|c|}{ Male } & \multicolumn{2}{c|}{ Female } & \multicolumn{2}{c|}{ Total } \\
\hline & Yes & No & Yes & No & Yes & No \\
\hline Medication & $100 \%$ & $0 \%$ & $97 \%$ & $3 \%$ & $97 \%$ & $3 \%$ \\
\hline Surgical Treatment & $100 \%$ & $0 \%$ & $61 \%$ & $39 \%$ & $68 \%$ & $32 \%$ \\
\hline $\begin{array}{c}\text { No need of anything, } \\
\text { just chill }\end{array}$ & $0 \%$ & $100 \%$ & $3 \%$ & $97 \%$ & $3 \%$ & $97 \%$ \\
\hline
\end{tabular}

Can CRC be treated with medication only? In the male category, $100 \%$ of the males answered Yes to this question and no one answered No. In the female category, according to $97 \%$ of females, CRC can be treated with medication, while the rest of $3 \%$ are against this question and their answer is No. The entire result of males and females in this category is as follows: $97 \%$ answered that it can be treated with medication only, while 3\% responded that it can't be treated with medication only. Can CRC be treated with Surgery? Again $100 \%$ of the males answered Yes and $0 \%$ answered No. In case of females, $61 \%$ of the females filled the column Yes, while the rest of $39 \%$ filled the column No. The combined results of males and females responses are described as follows: $68 \%$ answered Yes it can be treated with surgery, while 32\% answered that it can't be treated with surgery. Do you think that CRC is an easily curable disease and you don't have to worry about it? The answer is again $100 \%$ but in the section No. No one answered Yes. $3 \%$ of the females answered Yes it is easily curable and you don't have to worry about CRC, while $97 \%$ of the females answered No. The collective results are as follows: $3 \%$ of the students answered that it is easily curable and you don't have to worry about it, while the rest of $97 \%$ responded that it can't be cured easily and you have to worry about it Table 5 demonstrate the knowledge of the students about the Possible Treatments available for CRC. 
In the questionnaire, the first question was about the causative agent for Colorectal Cancer. There were five options i.e. viral disease, bacterial disease, fungal disease, genetic disease and metabolic disease. According to majority of the students i.e. 78\%, CRC is a bacterial disease which shows the main causative agent for CRC is a bacterium. In 2008 a review was published about the causative agents for CRC. According to that paper different factors contribute towards this deadly disease i.e. CRC. It was believed that there is a strong link between CRC and some of the hereditary gene mutations but only mutation was not the basic reason for CRC. According to one study only 3-5\% of the CRC cases were due to these hereditary mutations. So, there are other possible reasons like poor diet, cigarette smoking, drinking alcohol etc. As the name indicates CRC is a cancer of colon and rectum, it starts in the epithelial lining of colon and rectum. Replication of the human colon cells is very fast so high replication rate is thought to be one of the reason to make it vulnerable for mutations. Another important aspect to consider was that human intestine may prove to be a best habitat for the growth of many different species of bacteria. Both types of bacteria i.e. pathogenic and non-pathogenic are present in the intestine and these pathogenic bacteria were thought to be responsible for causing CRC. In addition to bacteria, human intestine is also susceptible to both pathogenic and non-pathogenic viruses. The four most common infectious agents to be considered are: Helicobacter pylori, Streptococcus bovis, JC virus (JCV), and Human Papillomavirus (HPV) [8]. So, CRC is not only caused by only bacteria but a number of factors act as a causative agent for CRC i.e. bacteria, viruses, hereditary gene mutations and poor diet etc.

The next question was about the victims and sufferers of Colorectal Cancer in your surroundings. There were a series of questions related to victims of CRC. More than $95 \%$ of students never witnessed any case of CRC in their family or vicinity. On average there are $4.5 \%$ chances of developing CRC, which is 1 in both among males and females. According to World Cancer Research Fund International, most cases of CRC were found in developed countries in 2012. Republic of Korea had highest rate of CRC while Slovakia and Hungary were $2^{\text {nd }}$ and $3^{\text {rd }}$ respectively [9].

Third category was about the transmission of Colorectal Cancer that how it is transmitted and what are the routes of transmission of CRC. There were two options about transmission of CRC; first option was, Can CRC be transmitted through contact and blood transfusion? And the second option was, Can CRC be transmitted from affected parents to offspring? About $11 \%$ of the students answered that Yes, CRC can be transmitted through contact and blood transfusion and 89\% answered No to this option. The transmission of CRC through contact and blood transfusion is highly unlikely to occur because the immune system of recipient is active enough to get rid of such cells. 38\% of the students answered that Yes CRC can be transmitted from affected parents to offspring while $62 \%$ answered No. There are numerous reasons that may cause an increase in an individual's risk to CRC but how these factors contribute towards CRC, is not yet clear. There are two types of genes when our cells divide:
I. Genes that cause uncontrolled division of cells and helps them to remain alive at all stages, are called as Oncogenes.

II. Genes that contribute towards controlled cell division and contribute in cell death at right time are called Tumor Suppressor Genes.

When there is an onset of cancer then these Oncogenes become active and deactivate the tumor suppressor genes and these changes may lead to Colorectal Cancer. There are some genetic mutations that can be passed on from parents to offspring and these types of mutations are called as Inherited Mutations. Very few cases of CRC are due to these inherited mutations but mostly the type of mutations that contribute towards the highest proportion of CRC cases are Acquired Mutations. Acquired mutations are not transferred from parents to offspring [10].

The last portion comprised the possible treatment methods of CRC and its level of worriness. There are three possible options which are: medicine, surgery and the last one to not to worry about CRC. 97\% of the students answered that CRC can be treated with medicines. CRC can be treated with drugs if the cancer is at its initial stages. Different chemotherapeutic drugs i.e. fluorouracil are available for the treatment of CRC. Fluorouracil in combination with Recombinant Interferon- $\alpha$ and some other agents (methotrexate, sparfosic acid, hydroxycarbamide (hydroxyurea), allopurinol, calcium folinate) may proved to be more effective treatment of CRC. Fluorouracil in addition with levamisole was also considered an efficient treatment. Chemotherapy in addition with radiotherapy was believed to be the most effective treatment before surgery [11]. Second option was about surgical treatment of CRC. According to $68 \%$ of the students, CRC can be treated with surgical treatment while $32 \%$ of the students answered that CRC cannot be treated even with surgery. Different surgical treatments are available depending upon the condition of patient and the stage of CRC. Other factors like age, ploidy, sex, perforation, genetic makeup of cancerous tissues, obstruction, and rectal bleeding may also help in deciding that which type of surgery is suitable for the patient. Local Excision Procedures which includes Transanal endoscopic microsurgery (TEM), Radical Resection, Total Mesorectal Excision (TME), Low Anterior Resection (LAR), Abdominal Perineal Resection (APR), Coloanal Anastomosis, Colonic Pouch Reservoir and Laparoscopy etc. are the available surgeries as a treatment for CRC [12]. The last option was about to worry or to not worry about the disease. 3\% of the students think that there is no need to worry about CRC and they are totally wrong because CRC is a deadly disease and it needs intensive care and therefore it can't be taken as lightly.

There has been a similar study regarding knowledge, practice and attitude towards CRC and its screening procedures among people of Hong Kong. And according to that study, 60.9\% people were unaware that CRC is very common type of cancer. $91.5 \%$ responded that there wasn't any case of CRC in their family [13]. In another study conducted among English population showed that only $10 \%$ of the participants were aware of the fact that CRC 
is ranked third among common type of cancers and merely $46 \%$ people knew some symptoms and risk factors of CRC [14]. There is another study regarding the awareness of CRC among the population of Perak state of Malaysia, and this study illustrated that 38\% people had no knowledge regarding CRC [15]. Another study indicates that majority of people of Makkah, Saudi Arabia are also unaware of CRC. 53.5\% were unaware of the symptoms of CRC and 92.2\% never had a screening test of CRC [16]. A study conducted among people of Oman suggested that $59.6 \%$ of them were unaware of basic symptoms and risk factors of CRC and others had poor understanding of screening procedures [17]. The overal global trend is that people lack basic knowledge regarding CRC. This trend is also very common in western countries.

\section{Conclusion}

This study emphasizes the importance of awareness of a dangerous disease Colorectal Cancer. Globally, colorectal carcinoma is considered as one of the most widespread cancers and also the second most principal cause of deaths after lung cancer. Although understanding and knowledge of CRC has noticeably improved and also new and better treatments have developed to treat this lethal type of cancer but still the expectation for the survival of the victim is less $[11,15,18]$ People have very less understanding and awareness of CRC.

All the results clearly demonstrate that there is a need to organize seminars regarding risk factors, causative agents, mortality rate, mode of transmission and the possible treatments etc. about CRC so that not only students but common folks can have awareness about CRC. Our survey highlights the need for conducting such awareness programs and campaigns to develop better understanding of CRC. The level of awareness regarding CRC is extremely low. Therefore, it is a need of time that different seminar and awareness programs must be conducted in order to aware the masses about risk factors, symptoms and timely treatment of CRC.

\section{References}

1. Sherr CJ (1996) Cancer cell cycles. Science 274(5293): 1672-1677.

2. Siegel RL, Miller KD, Jemal A (2018) Cancer statistics, 2018. CA: a cancer journal for clinicians 68(1): 7-30.

3. Adrouny AR (2002) Understanding colon cancer, Univ. Press of Mississippi, USA.
4. Haggar FA, Boushey RP (2009) Colorectal cancer epidemiology: incidence, mortality, survival, and risk factors. Clin Colon Rectal Surg 22(4): 191-197.

5. Fijten GH, Starmans R, Muris JW, Schouten HJ, Blijham GH, et al. (1995) Predictive value of signs and symptoms for colorectal cancer in patients with rectal bleeding in general practice. Fam Pract 12(3): 279-286.

6. Astin M, Griffin T, Neal RD, Rose P, Hamilton W (2011) The diagnostic value of symptoms for colorectal cancer in primary care: a systematic review. Br J Gen Pract 61(568): e231-e243.

7. Majumdar SR, Fletcher RH, Evans AT (1999) How does colorectal cancer present? Symptoms, duration, and clues to location. Am J Gastroenterol 94(10): 3039-3045

8. Burnett-Hartman AN, Newcomb PA, Potter JD (2008) Infectious agents and colorectal cancer: a review of Helicobacter pylori, Streptococcus bovis, JC virus, and human papillomavirus. Cancer Epidemiology and Prevention Biomarkers 17(11): 2970-2979.

9. Ferlay J, Soerjomataram I, Dikshit R, Eser S, Mathers C, et al. (2015) Cancer incidence and mortality worldwide: sources, methods and major patterns in GLOBOCAN 2012. Int J Cancer 136(5): E359-E386.

10. Libutti SK, Saltz LB, Willett CG, Levine RA (2015) Cancer of the colon. Rosenberg's Cancer: Principles \& Practice of Oncology, In: DeVita \& Hellman, $\left(10^{\text {th }}\right.$ Edn), Wolters Kluwer Health Adis (ESP), UK.

11. Labianca R, Pessi MA, Zamparelli G (1997) Treatment of colorectal cancer. Drugs 53: 593-607.

12. Guillem JG, Paty PB, Cohen AM (1997) Surgical treatment of colorectal cancer. CA: a cancer journal for clinicians 47(2): 113-128.

13. Wong GCY, Lee KY, Lam KF, Fan SYS (2017) Community-based survey of knowledge of, attitudes to and practice of colorectal cancer screening in Hong Kong. Journal of digestive diseases 18(10): 582-590.

14. Niksic M, Forbes LJ (2018) Awareness of Colorectal Cancer: Recognition of Symptoms and Risk Factors by Socio-demographic Characteristics, in Timely Diagnosis of Colorectal Cancer pp. 1-20.

15. Su TT, Goh JY, Tan J, Muhaimah AR, Pigeneswaren Y, et al. (2013) Level of colorectal cancer awareness: a cross sectional exploratory study among multi-ethnic rural population in Malaysia. BMC cancer 13: 376.

16. Al-Maghrabi AA (2016) Assessment of the knowledge and awareness of colorectal cancer among general population of Makkah: a survey based study. International Journal of Academic Scientific Research 4(4): 168175.

17. Al-Azri M, Al-Hamedi I, Al-Awisi H, Al-Hinai M, Davidson R (2015) Public awareness of warning signs and symptoms of cancer in oman: a community-based survey of adults. Asian Pac J Cancer Prev 16(7): 27312737.

18. Sankaranarayanan R, Swaminathan R, Brenner H, Chen K, Chia KS, et al. (2010) Cancer survival in Africa, Asia, and Central America: a population-based study. Lancet Oncol 11(2): 165-173.
Creative Commons Attribution 4.0 International License

For possible submissions Click Here

\section{Submit Article}

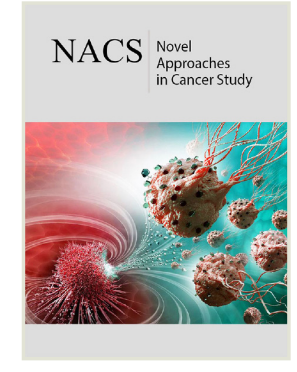

\section{Novel Approaches in Cancer Study}

Benefits of Publishing with us

- High-level peer review and editorial services

- Freely accessible online immediately upon publication

- Authors retain the copyright to their work

- Licensing it under a Creative Commons license

- Visibility through different online platforms 